\title{
Quantification of emphysema with preoperative computed tomography has stronger association with pulmonary complications than pulmonary function test results after pulmonary lobectomy
}

\author{
Kwon Joong Na, MD, ${ }^{a}$ Chang Hyun Kang, MD, PhD, ${ }^{a}$ Jae Hyun Jeon, MD, ${ }^{a}$ Yong Won Seong, MD, \\ In Kyu Park, MD, $\mathrm{PhD},{ }^{\mathrm{a}} \mathrm{Jin} \mathrm{Mo} \mathrm{Goo}, \mathrm{MD}, \mathrm{PhD},{ }^{\mathrm{c}}$ and Young Tae Kim, $\mathrm{MD}, \mathrm{PhD}^{\mathrm{a}}$
}

\begin{abstract}
Objective: To determine whether the percentile quantification of emphysema with computed tomography has a stronger association with pulmonary complications than pulmonary function testing after pulmonary lobectomy.

Methods: The patients who underwent pulmonary lobectomy and also had thin-section chest computed tomography scans available from July 2009 through August 2011 were reviewed. The patients were divided into 2 groups according to whether they had a history of chronic obstructive pulmonary disease. The emphysema index (EI) was defined as the volumetric percentage of the areas of low computed tomography attenuation, which was measured using automatic analysis software. Receiver operating characteristic curve analysis was used to compare the predictability of pulmonary complications, and multivariate analyses were performed to determine the risk factors for pulmonary complications.
\end{abstract}

Results: A total of 280 patients were evaluated. Pulmonary complications occurred in 37 patients (13.2\%). The median EI was 9.30 (range, 0.04-37.27). The area under the receiver operating characteristic curve was significantly greater for the EIs than for the pulmonary function testing values. The cutoff EI value was 11.46 , and the sensitivity and specificity was $83.8 \%$ and $74.1 \%$, respectively. EI, male gender, and diffusing capacity $<80 \%$ were risk factors for pulmonary complications for all patients; EI and age $>70$ years were risk factors for patients without chronic obstructive pulmonary disease; and EI and diffusing capacity $<80 \%$ were risk factors for patients with chronic obstructive pulmonary disease.

Conclusions: The EI is a significant risk factor for pulmonary complications after pulmonary lobectomy and had stronger association with them than did pulmonary function testing. The EI might serve as a useful tool for evaluating risk before pulmonary lobectomy. (J Thorac Cardiovasc Surg 2014;147:915-20)

Pulmonary risk stratification and assessment are crucial steps in treating patients undergoing major lung resection surgery. Postoperative pulmonary complications, in particular, have been associated with increased mortality and hospital costs and prolonged hospital stays, despite notable advancements in perioperative care and surgical skill. Various tests have been used to identify the patients at high risk of developing complications after a major lung resection. Of these, the pulmonary function test (PFT) has

From the Department of Thoracic and Cardiovascular Surgery, ${ }^{\mathrm{a}}$ Seoul National University Hospital, Seoul National University College of Medicine, Seoul, South Korea; Department of Thoracic and Cardiovascular Surgery, ${ }^{\mathrm{b}}$ SMG-SNU Boramae Medical Center, Seoul, South Korea; and Department of Radiology, ${ }^{\mathrm{c}}$ Seoul National University Hospital, Seoul National University College of Medicine, Seoul, South Korea.

Disclosures: Jin Mo Goo reports lecture fees from Siemens, Bayer, and Gerbet. All other authors have nothing to disclose with regard to commercial support.

Read at the 39th Annual Meeting of The Western Thoracic Surgical Association, Coeur d'Alene, Idaho, June 26-29, 2013.

Received for publication June 25, 2013; revisions received Oct 5, 2013; accepted for publication Nov 12, 2013; available ahead of print Jan 13, 2014.

Address for reprints: Chang Hyun Kang, MD, PhD, Department of Thoracic and Cardiovascular Surgery, Seoul National University Hospital, Seoul National University College of Medicine, 101 Daehak-ro, Jongno-gu, Seoul 110-744, Korea (E-mail: chkang@snu.ac.kr).

$0022-5223 / \$ 36.00$

Copyright (c) 2014 by The American Association for Thoracic Surgery

http://dx.doi.org/10.1016/j.jtcvs.2013.11.029 been considered the reference standard. ${ }^{1-6}$ The predicted values of the preoperative and postoperative forced expiratory volume in 1 second $\left(\mathrm{FEV}_{1}\right)$ and the diffusion capacity of carbon monoxide $\left(\mathrm{D}_{\mathrm{LCO}}\right)$ have been the 2 most common parameters used for predicting postoperative morbidity and mortality. ${ }^{2-6}$

Emphysema is a characteristic parenchymal destruction condition that is 1 of the forms of chronic obstructive pulmonary disease (COPD). It has been assessed in greater detail because of major developments in multidetector computed tomography (CT) techniques. This assessment has been referred to as the emphysema index (EI) in many studies. Significant correlations have been found for the EI, pathologic emphysema grade, and PFT results. ${ }^{7}$ Thus, the severity of the EI has been regarded as a prognostic factor and a predictor of mortality in patients with COPD or lung cancer in several studies. ${ }^{8,9}$ The use of the EI as a tool for evaluating the risk of pulmonary complications after lung resection, however, has never been reported.

The objectives of the present study were to (1) evaluate the predictability of the EI for pulmonary complications after pulmonary lobectomy, (2) compare the predictive values of EI with that of PFT, and (3) identify the significant risk factors for pulmonary complications using multivariate analyses. 


\author{
Abbreviations and Acronyms \\ AUC = area under the receiver operating \\ characteristic curve \\ $\mathrm{CI}=$ confidence interval \\ $\mathrm{COPD}=$ chronic obstructive pulmonary disease \\ $\mathrm{D}_{\text {LCO }}=$ diffusion capacity of carbon monoxide \\ EI $=$ emphysema index \\ $\mathrm{FEV}_{1}=$ forced expiratory volume in 1 second \\ $\mathrm{FVC}=$ forced vital capacity \\ PFT = pulmonary function test \\ $\mathrm{ROC}=$ receiver operating characteristics
}

\section{METHODS}

The institutional review board reviewed the study protocol and approved it as a minimal risk retrospective study (approval no. H-1303082-474). Additionally, the study did not require individual patient consent according to the institutional guidelines for consent waivers.

A retrospective record review of a prospectively collected thoracic database was conducted for all patients undergoing anatomic lobectomy from July 2009 through August 2011. The present review also included those patients who had undergone preoperative thin-section chest CT at our institution. The following exclusion criteria were applied: bilobectomy or pneumonectomy, previous thoracic surgery, a history of interstitial lung disease, or concomitant resection of the diaphragm or chest wall. The subjects were divided into 2 groups, those with and without COPD. COPD was defined as a $\mathrm{FEV}_{1}$ /forced vital capacity (FVC) ratio of $<0.7 .{ }^{10}$

All postoperative pulmonary complications were recorded prospectively and were characterized as $\geq 1$ of the following: atelectasis requiring bronchoscopic toileting, pneumonia, reintubation for respiratory failure, a requirement for tracheostomy, or acute respiratory distress syndrome.

\section{PFT Values}

Using the American Thoracic Society criteria, the PFT measurements were performed using a spirometer (SPFS/D, MedGraphics, St Paul, Minn) with the patients sitting in an upright position. ${ }^{11}$

The following values were evaluated: $\mathrm{FVC}, \mathrm{FEV}_{1}, \mathrm{FEV}_{1} / \mathrm{FVC}$ ratio, and $\mathrm{D}_{\mathrm{LCO}}$. All spirometric values are expressed as a percentage of the measured value in relation to the predicted value. All patients underwent PFTs within 1 month of surgery.

\section{CT Acquisition Parameters}

The chest CT scans were performed using the following scanners: the Somatom Definition, Sensation-16 (Siemens Medical Solutions, Forchheim, Germany), Brilliance-64 (Phillips Medical Systems, Best, The Netherlands), and Discovery CT 750HD (GE Healthcare, Milwaukee, Wis). The scanner parameters were set at $120 \mathrm{kVp}, 100$ to $200 \mathrm{~mA}$, a 0.875 to 1.5 pitch, and a 1 - to $1.25-\mathrm{mm}$ collimation. The CT images were acquired after the patients had been intravenously administered a $100-\mathrm{mL}$ injection of contrast media. The images, with a thickness of 1 to $1.25 \mathrm{~mm}$, were reconstructed using a medium-sharp reconstruction algorithm. All CT scans were obtained with each patient placed in the supine position and at full inspiration. All patients had undergone preoperative CT scans within 1 month of surgery.

\section{Emphysema Quantification}

The measurements of the quantitative analysis of lung parenchyma were obtained using an automated lung image analysis tool (Thoracic VCAR, GE Healthcare), which was installed on an image processing workstation
(AW Server, version 2, GE Healthcare) for each data set. The total lung volume and EI, as represented by the relative area under a threshold of -950 Hounsfield units, were also obtained. The degree of emphysema was assessed and quantified by segmenting the lung parenchyma and airways from the chest wall and large central blood vessels. The total emphysema percentage was defined as all lung voxels less than a certain CT attenuation value. Previous studies have validated an attenuation threshold value of -950 Hounsfield units for the quantitative analysis of an EI (Figure 1). ${ }^{12}$

\section{Statistical Analysis}

Receiver operating characteristic (ROC) curve analysis was used to compare the utility of PFT versus EI in predicting pulmonary complications. The areas under the ROC curves (AUCs) are presented with the $95 \%$ confidence intervals (CIs). The statistical significance of the differences in the pulmonary complication predictability was determined by comparing the AUCs of the patients' EIs and PFTs using nonparametric methods previously described by DeLong and colleagues, ${ }^{13}$ followed by Bonferroni's adjustment. The cutoff value and sensitivity and specificity were determined by measuring the point on the ROC curve with the shortest distance from the upper left corner. The perioperative patient characteristics associated with pulmonary complications were identified by univariate analysis. All parameters for the analysis were analyzed with parametric (Pearson's $\chi^{2}$, Fisher's exact, or Student's $t$ test) and nonparametric

TABLE 1. Baseline characteristics, demographics, comorbidities, and operative data

\begin{tabular}{|c|c|c|c|}
\hline Characteristic & $\begin{array}{c}\text { All patients } \\
(\mathbf{n}=\mathbf{2 8 0})\end{array}$ & $\begin{array}{c}\text { Complications } \\
(\mathbf{n}=\mathbf{3 7}) \\
\end{array}$ & $\begin{array}{c}\text { No } \\
\text { complications } \\
(\mathrm{n}=\mathbf{2 4 3}) \\
\end{array}$ \\
\hline Age $(y)$ & $64.1 \pm 9.8$ & $69.9 \pm 7.7$ & $63.2 \pm 9.8$ \\
\hline Age $>70 y$ & $80(28.6)$ & $18(48.6)$ & $62(25.5)$ \\
\hline Male gender & $161(57.5)$ & $36(97.3)$ & $125(51.4)$ \\
\hline Smoking & $137(48.9)$ & $31(83.8)$ & $106(43.6)$ \\
\hline \multicolumn{4}{|l|}{ Comorbidities } \\
\hline Pulmonary tuberculosis & $37(13.2)$ & $5(13.5)$ & $32(13.2)$ \\
\hline Hypertension & $84(30.0)$ & $13(35.1)$ & $71(29.2)$ \\
\hline Diabetes mellitus & $28(10.0)$ & $6(16.2)$ & $22(9.1)$ \\
\hline COPD & $109(38.9)$ & $28(75.7)$ & $81(33.3)$ \\
\hline Lung cancer & $261(93.2)$ & $37(100)$ & $224(92.2)$ \\
\hline Neoadjuvant treatment & $16(5.7)$ & $3(8.1)$ & $13(5.3)$ \\
\hline \multicolumn{4}{|l|}{ EI } \\
\hline Median & 9.30 & 17.99 & 7.98 \\
\hline Range & $0.04-37.27$ & $2.26-37.27$ & $0.04-27.88$ \\
\hline \multicolumn{4}{|l|}{ PFT (predictive $\%$ value) } \\
\hline $\mathrm{FEV}_{1}$ & $99.7 \pm 19.4$ & $89.9 \pm 20.0$ & $101.1 \pm 18.9$ \\
\hline $\mathrm{FEV}_{1}<70 \%$ & $18(6.4)$ & $5(13.5)$ & $13(5.3)$ \\
\hline FVC & $100.5 \pm 14.8$ & $101.4 \pm 18.4$ & $100.3 \pm 14.2$ \\
\hline $\mathrm{FEV}_{1} / \mathrm{FVC}$ & $71.2 \pm 10.4$ & $61.7 \pm 13.9$ & $72.7 \pm 8.9$ \\
\hline $\mathrm{D}_{\mathrm{LCO}}$ & $95.7 \pm 19.2$ & $87.6 \pm 20.8$ & $96.9 \pm 18.7$ \\
\hline $\mathrm{D}_{\mathrm{LCO}}<80 \%$ & $57(20.4)$ & $16(43.2)$ & $41(16.9)$ \\
\hline Thoracotomy & 109 (38.9) & $22(59.5)$ & $87(35.8)$ \\
\hline VATS & $171(61.1)$ & $15(8.8)$ & $156(91.2)$ \\
\hline \multicolumn{4}{|l|}{ Operation side } \\
\hline Right & $174(62.1)$ & $25(67.6)$ & $149(85.6)$ \\
\hline Left & $106(37.9)$ & $12(11.3)$ & $94(88.7)$ \\
\hline
\end{tabular}

Data presented as mean \pm standard deviation, $\mathrm{n}(\%)$, or median and range. $C O P D$, Chronic obstructive pulmonary disease; EI, emphysema index; PFT, pulmonary function test; $F E V_{l}$, forced expiratory volume in 1 second; $F V C$, forced vital capacity; $D_{L C O}$, diffusion capacity of carbon monoxide; VATS, video-assisted thoracoscopic surgery. 


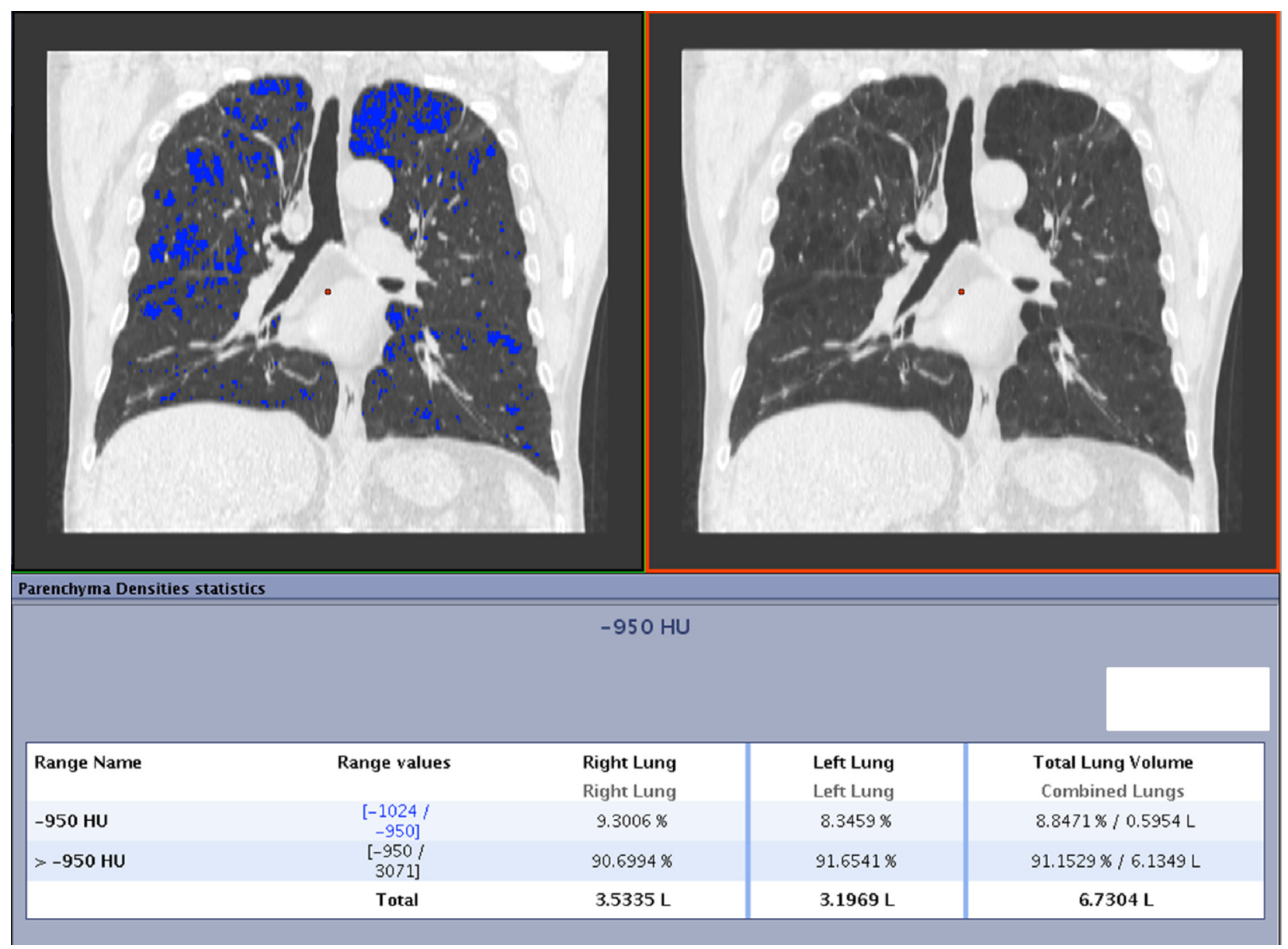

FIGURE 1. Quantitative measurements of emphysema using the automated lung image analysis tool (Thoracic VCAR, GE Healthcare).

(Mann-Whitney $U$ test) tests, as applicable. The variables with $P<.10$ were used as the covariates for the multivariate logistic regression analyses, with pulmonary complications set as the dependent variable. In previous studies, it had been demonstrated that the usefulness of PFTs in assessing operative risk could be changed if a patient had a history of COPD; therefore, univariate analyses and multivariate logistic regression models were repeated separately for the groups of patients who did or did not have a history of COPD. ${ }^{5}$ All results are presented as the mean \pm standard deviation or proportions. The cutoff values from the ROC curves were measured using MedCalc statistical software, version 8.1 (MedCalc Software, Ostend, Belgium). Other statistical analyses were performed using the Statistical Analysis Systems software package, version 9.2 (SAS Institute, Cary, NC).

\section{RESULTS}

During the study period, 1128 patients underwent major lung resections. Of these patients, 280 , who had undergone pulmonary lobectomy and preoperative chest CT with the described protocol, were included in the present study. The excluded patients had undergone thick-section chest CT at another hospital or other department at our center and had been referred to us for surgery. We did not perform additional thin-section chest CT for those patients. The patients' demographic data, baseline characteristics, comorbidities, and operative data are summarized in Table 1 . The overall operative mortality rate was $1.8 \%$ (5 patients). The median chest tube duration for all patients was 6 days, and the median length of hospital stay was 9 days. A total of 55 pulmonary complications occurred in 37 patients $(13.2 \%)$, including pneumonia in 21 patients $(7.5 \%)$, atelectasis requiring bronchoscopic toileting in $23(8.2 \%)$, reintubation in $5(1.8 \%)$, tracheostomy in $2(0.7 \%)$, and acute respiratory distress syndrome in 4 patients $(1.4 \%)$. All cases of acute respiratory distress syndrome developed secondary to pneumonia. The median EI value was greater for the patients with pulmonary complications (17.99 [range, 2.26-37.27] for patients with complications vs 7.98 [range, 0.04-27.88] for those without). The EI distributions were significantly different between the 2 groups $(P<.0001)$.

The ROC curve analysis is shown in Figure 2. The AUC was $0.832(95 \% \mathrm{CI}, 0.768-0.897)$ for the EI, $0.741(95 \%$ CI, 0.644-0.837) for the $\mathrm{FEV}_{1} / \mathrm{FVC}$ ratio, $0.664(95 \%$ CI, 0.566-0.762) for the $\mathrm{FEV}_{1}$, and $0.632(95 \% \mathrm{CI}$, 0.523-0.741) for the $\mathrm{D}_{\mathrm{LCO}}$. The predictive power (AUC) was significantly greater for the EI than for $\mathrm{FEV}_{1}$ and 


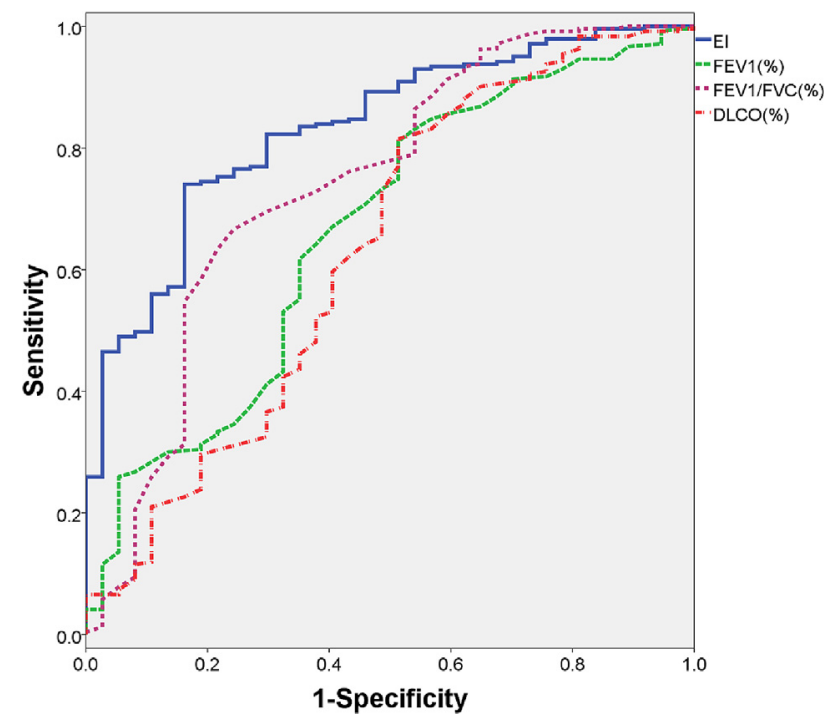

FIGURE 2. Comparison of the emphysema index (EI) and the predictive percentage value of the pulmonary function test using a receiver operating characteristic curve analysis. The area under the curve was 0.832 for EI, 0.741 for forced expiratory volume in 1 second $\left(F E V_{1}\right) /$ forced vital capacity $(F V C), 0.664$ for $\mathrm{FEV}_{1}$, and 0.632 for the diffusion lung capacity to carbon monoxide $\left(D_{L C O}\right)$.

$\mathrm{D}_{\mathrm{LCO}}$ (EI vs $\mathrm{FEV}_{1}, P=.0087$; EI vs $\mathrm{D}_{\mathrm{LCO}}, P=.0041$ ). The cutoff for EI with the greatest predictive ability for pulmonary complications was 11.46 , with a sensitivity and specificity of $83.8 \%$ and $74.1 \%$, respectively.

Significant risk factors for pulmonary complications were identified using multivariate analysis for all study

TABLE 2. Risk factor analysis results for pulmonary complications in all patients

\begin{tabular}{|c|c|c|c|c|}
\hline \multirow[b]{2}{*}{ Variable } & \multicolumn{2}{|l|}{ Univariate } & \multicolumn{2}{|l|}{ Multivariate } \\
\hline & OR $(95 \%$ CI $)$ & $\begin{array}{c}P \\
\text { value }\end{array}$ & OR $(95 \%$ CI $)$ & $\begin{array}{c}P \\
\text { value }\end{array}$ \\
\hline Thoracotomy & $2.63(1.30-5.33)$ & .006 & & \\
\hline Age $>70 y$ & $2.77(1.37-5.60)$ & .004 & & \\
\hline Male gender & $33.98(4.59-251.83)$ & $<.001$ & $19.91(2.47-160.34)$ & .005 \\
\hline EI & & $<.001$ & $1.13(1.07-1.20)$ & $<.001$ \\
\hline $\begin{array}{l}\mathrm{FEV}_{1} / \mathrm{FVC} \\
\quad<70 \%\end{array}$ & $6.22(2.80-13.81)$ & $<.001$ & & \\
\hline $\mathrm{FEV}_{1}<70 \%$ & $2.76(0.92-8.27)$ & .072 & & \\
\hline $\mathrm{D}_{\mathrm{LCO}}<80 \%$ & $3.75(1.81-7.80)$ & $<.001$ & $5.72(2.14-15.27)$ & .001 \\
\hline Smoking & $6.68(2.69-16.59)$ & $<.001$ & & \\
\hline $\begin{array}{l}\text { Pulmonary } \\
\text { tuberculosis }\end{array}$ & & 1.000 & & \\
\hline Hypertension & & .464 & & \\
\hline Diabetes mellitus & & .176 & & \\
\hline Lung cancer & $1.17(1.11-1.22)$ & .088 & & \\
\hline $\begin{array}{c}\text { Neoadjuvant } \\
\text { treatment }\end{array}$ & & .453 & & \\
\hline
\end{tabular}

patients. The EI, male gender, and $\mathrm{D}_{\mathrm{LCO}}<80 \%$ were identified as significant risk factors (Table 2). When patients were analyzed separately according to their history of COPD, the EI and $\mathrm{D}_{\mathrm{LCO}}<80 \%$ were identified as risk factors for patients with COPD, and EI and age $>70$ years were identified as risk factors for patients without COPD (Table 3).

\section{DISCUSSION}

The present study has demonstrated 2 major findings. First, the EI had a significantly stronger association with pulmonary complications than did the $\mathrm{FEV}_{1}$ and $\mathrm{D}_{\mathrm{LCO}}$. Second, patients with high EIs had a greater risk of developing pulmonary complications after pulmonary lobectomy, regardless of a history of COPD.

An accurate assessment of patients at a high risk of complications after major lung resection is important for many reasons. It could help clinicians determine operability, obtain informed consent, and provide the optimal treatment options to patients. Preoperative PFT has been the most powerful tool that surgeons have used to predict the risk of complications after major lung resection for many decades, with $\mathrm{FEV}_{1}$ and $\mathrm{D}_{\mathrm{LCO}}$ the 2 most commonly used parameters. ${ }^{1-6}$ However, some studies have reported that PFTs cannot accurately predict morbidity and mortality. ${ }^{14,15}$ Many ongoing investigations are attempting to establish the best risk-stratification model for postoperative pulmonary complications.

Recently, interest has been renewed in the imaging of emphysema because of improved CT detection and quantification techniques. ${ }^{7}$ With the introduction of the multidetector CT, it is now possible to obtain highresolution CT scans volumetrically for the entire lung. This approach has been shown to be suitable for assessing emphysema. ${ }^{7,16}$ Emphysema has been pathologically characterized as the destruction of airways distal to the terminal bronchioles, and it is radiologically characterized by areas of abnormally low attenuation that contrast with the surrounding lung parenchyma, which will have normal CT attenuation values. ${ }^{7,16}$ Some approaches have been made to objectively quantify emphysema using CT scans. In the present study, we used a threshold technique that defines emphysema by the area below a specific threshold attenuation value. ${ }^{7} \mathrm{We}$ set $-950 \mathrm{HU}$ as the threshold attenuation value, because it has been proved to be a valuable parameter for quantifying emphysema using CT scans by Gevenois and colleagues. ${ }^{12}$

The clinical usefulness of emphysema quantification by $\mathrm{CT}$ scan assessment (CT/emphysema quantification) has been demonstrated in previous studies. These studies reported good correlations between CT/emphysema quantification and the PFT results and reported that CT/emphysema quantification might also predict mortality in certain patient groups. ${ }^{7-9,17}$ Stimulated by the findings of 
TABLE 3. Risk factor analysis results for pulmonary complications in patients with and without COPD

\begin{tabular}{|c|c|c|c|c|c|c|c|c|}
\hline \multirow[b]{3}{*}{ Variable } & \multicolumn{4}{|c|}{ Patients with COPD } & \multicolumn{4}{|c|}{ Patients without COPD } \\
\hline & \multicolumn{2}{|c|}{ Univariate } & \multicolumn{2}{|c|}{ Multivariate } & \multicolumn{2}{|l|}{ Univariate } & \multicolumn{2}{|c|}{ Multivariate } \\
\hline & OR $(95 \%$ CI $)$ & $P$ value & OR $(95 \%$ CI $)$ & $P$ value & OR $(95 \%$ CI $)$ & $P$ value & OR $(95 \%$ CI $)$ & $P$ value \\
\hline Thoracotomy & & .246 & & & $4.35(1.05-18.10)$ & .062 & & \\
\hline Age $>70 y$ & & .682 & & & $5.98(1.51-23.69)$ & .014 & $7.63(1.47-39.60)$ & .016 \\
\hline Male gender & $1.42(1.25-1.63)$ & .011 & & & $13.97(1.71-114.43)$ & .003 & & \\
\hline EI & & $<.001$ & $1.12(1.05-1.20)$ & .001 & & .003 & $1.17(1.03-1.31)$ & .012 \\
\hline $\mathrm{FEV}_{1}<70 \%$ & & .551 & & & & 1.000 & & \\
\hline DLCO $<80 \%$ & $3.81(1.50-9.67)$ & .004 & $3.84(1.19-12.40)$ & .024 & & .180 & & \\
\hline Smoking history & & .204 & & & $8.31(1.67-41.47)$ & .005 & & \\
\hline Pulmonary tuberculosis & & .552 & & & & .284 & & \\
\hline Hypertension & & .726 & & & & .253 & & \\
\hline Diabetes mellitus & & .527 & & & & .518 & & \\
\hline Lung cancer & & .335 & & & & 1.000 & & \\
\hline Neoadjuvant treatment & & 1.000 & & & & .357 & & \\
\hline
\end{tabular}

these previous studies, we hypothesized that CT/ emphysema quantification would have an intimate relationship with pulmonary complications after lung resection surgery if it correlated strongly with the PFT results and predicted mortality in patients with COPD. The present study has demonstrated that the EI (determined from emphysema quantification by CT scan assessment) had a significantly greater association with pulmonary complications after pulmonary lobectomy than did $\mathrm{FEV}_{1}$ and $\mathrm{D}_{\mathrm{LCO}}$. Our findings are supported by those of previously published reports that have suggested that CT scans are more sensitive than PFTs in detecting mild emphysema. ${ }^{18,19}$ These reports also revealed that EI reflects the pathologic lung destruction changes before pulmonary functions become impaired. In our study, a number of patients had normal pulmonary function but also had lungs with various degrees of emphysema, as determined from their preoperative CT scans. The EI was relatively high in this group, and some of these patients developed pulmonary complications postoperatively.

In our study, the patients had various perioperative characteristics (eg, thoracotomy, old age) that are proven risk factors for pulmonary complications. 3,4,6 Therefore, we addressed whether the patients with a high EI were at greater risk of pulmonary complications after controlling for such confounders with logistic regression analyses. A high EI and low $\mathrm{D}_{\mathrm{LCO}}$ were significant independent risk factors for all study patients. This finding is consistent with previous reports, in which $\mathrm{D}_{\text {LCO }}$ was an independent significant risk factor for pulmonary complications. ${ }^{1,2,4-6}$ In a subgroup analysis, a high EI and old age were significant risk factors for pulmonary complications in patients without COPD; however, high EI and low $\mathrm{D}_{\mathrm{LCO}}$ were determined to be significant in patients with COPD. In keeping with the ROC curve analysis results, we found that EI was an independent significant risk factor for predicting pulmonary complications, regardless of COPD history.

The present study had some limitations that must be acknowledged. First, our study was a retrospective review from a single institution. Randomized controlled or prospective study designs would be necessary to solidify the findings from our study. Second, the EI has not been validated in any other previous studies. It must be validated to exhibit its predictability for pulmonary complications after major lung resection. Third, our study group only included patients who had undergone lobectomy. To prove its usability in the preoperative risk assessment for major lung resection, patients undergoing bilobectomy and pneumonectomy should be included in future studies. Fourth, the section thickness and CT scanners were not standardized in the present study. Nevertheless, because all patients underwent thin-section CT scans (ranging from 1 to $1.25 \mathrm{~mm}$ in thickness), we assumed only subtle differences would be present in the emphysema quantifications. Although the effect of the CT scanners did not significantly influence the CT/emphysema quantification in some previous studies, we would recommend standardizing the CT scanners in future studies for a more accurate analysis. $^{20,21}$ Fifth, all patients were exposed to a standard radiation dose for their $\mathrm{CT}$ scan with intravenous contrast media. It has been reported that the radiation dose and contrast media could affect emphysema quantification and that a low-radiation-dose CT scan without contrast media has been shown to have the least effect on emphysema quantification. ${ }^{22,23}$ Although the radiation dose and the amount of contrast media were standardized for all patients in the present study, we would recommend performing low-dose CT scans without intravenous contrast media to more accurately quantify emphysema in future studies. 


\section{CONCLUSIONS}

From the results of our study, we would recommend using the EI from a preoperative CT scan for patients undergoing pulmonary lobectomy to help clinicians more accurately evaluate those who might be at high risk of developing pulmonary complications. The EI has high reproducibility and is easy to calculate using automatic analysis software; therefore, we believe that it will serve as a valuable tool in risk evaluation before pulmonary lobectomy for thoracic surgeons. ${ }^{24}$ Nevertheless, because our study also demonstrated that both EI and low $\mathrm{D}_{\mathrm{LCO}}$ were significant risk factors for pulmonary complications (consistent with previous reports), clinicians must consider the EI in combination with PFTs for a more accurate preoperative risk evaluation.

The authors thank Min-Jeong Yun from the General Electronics for her assistance in providing and running the automatic analysis software. The authors also thank the Medical Research Collaborating Center of Seoul National University Hospital for assisting with the statistical analyses.

\section{References}

1. Colice GL, Shafazand S, Griffin JP, Keenan R, Bolliger CT. Physiologic evaluation of the patient with lung cancer being considered for resectional surgery. ACCP evidenced-based clinical practice guidelines (2nd edition). Chest. 2007;132(3 Suppl):161S-77S.

2. Ferguson MK, Reeder LB, Mick R. Optimizing selection of patients for major lung resection. J Thorac Cardiovasc Surg. 1995;109:275-83.

3. Kearney DJ, Lee TH, Reilly JJ, DeCamp MM, Sugarbaker DJ. Assessment of operative risk in patients undergoing lung resection. Chest. 1994;105:753-9.

4. Wang J, Olak J, Ultmann RE, Ferguson MK. Assessment of pulmonary complications after lung resection. Ann Thorac Surg. 1999;67:1444-7.

5. Ferguson MK, Henning AG, Grab JD, Sheng S. Pulmonary complications after lung resection in the absence of chronic obstructive pulmonary disease: the predictive role of diffusing capacity. J Thorac Cardiovasc Surg. 2009;138:1297-302.

6. Brunelli A, Refai MA, Salati M, Sabbatini A, Morgan-Hughes NJ, Rocco G. Carbon monoxide lung diffusion capacity improves risk stratification in patients without airflow limitation: evidence for systematic measurement before lung resection. Eur J Cardiothorac Surg. 2006;26:567-70.

7. Litmanovich D, Boiselle PM, Bankier AA. CT of pulmonary emphysemacurrent status, challenges, and future directions. Eur Radiol. 2009;19:537-51.

8. Haruna A, Muro S, Nakano Y, Ohara T, Hoshino Y, Ogawa E, et al. CT scan findings of emphysema predict mortality in COPD. Chest. 2010;138:635-40.
9. Zulueta JJ, Wisnivesky JP, Henschke CI, Yip R, Farooqi AO, McCauley DI, et al. Emphysema scores predict death from COPD and lung cancer. Chest. 2012;141: 1216-23.

10. Pouwels RA, Buist AS, Calverley PM, Jenkins CR, Hurd SS; GOLD Scientific Committee. Global strategy for the diagnosis, management and prevention of chronic obstructive pulmonary disease. NHLBI/WHO Global Initiative for Chronic Obstructive Lung Disease (GOLD). Workshop summary. Am J Respir Crit Care Med. 2001;163:1256-76.

11. Standardization of spirometry, 1994 update. American Thoracic Society. Am J Respir Crit Care Med. 1995;152:1107-36.

12. Gevenois PA, de Maertelaer V, De Vuyst P, Zanen J, Yernault JC. Comparison of computed density and macroscopic morphometry in pulmonary emphysema. Am J Respir Crit Care Med. 1995;152:653-7.

13. DeLong ER, DeLong DM, Clarke-Pearson DL. Comparing the areas under two or more correlated receiver operating characteristic curves: a nonparametric approach. Biometrics. 1988;44:837-45.

14. Keagy BA, Schorlemmer GR, Murray GF, Starek PJ, Wilcox BR. Correlation of preoperative pulmonary function testing with clinical course in patients after pneumonectomy. Ann Thorac Surg. 1983;36:253-7.

15. Berry MF, Villamizar-Ortiz NR, Tong BC, Burfeind WR Jr, Harpole DH, D'Amico TA, et al. Pulmonary function tests do not predict pulmonary complications after thoracoscopic lobectomy. Ann Thorac Surg. 2010;89: 1044-52.

16. Madani A, Zanen J, de Maertelaer V, Gevenois PA. Pulmonary emphysema: objective quantification at multi-detector row CT-comparison with macroscopic and microscopic morphometry. Radiology. 2006;238:1036-43.

17. Moloney F, McWilliams S, Crush L, Laughlin PD, Kenneddy M, Henry M, et al. CT densitometry as a predictor of pulmonary function in lung cancer patients. Open Respir Med J. 2012;6:139-44.

18. Sanders C, Nath PH, Bailey WC. Detection of emphysema with computed tomography: correlation with pulmonary function tests and chest radiography. Invest Radiol. 1988;23:262-6.

19. Uppaluri R, Mitsa T, Sonka M, Hoffman EA, McLennan G. Quantification of pulmonary emphysema from lung computed tomography images. Am J Respir Crit Care Med. 1997;156:248-54.

20. Bakker ME, Stolk J, Putter H, Shaker SB, Parr DG, Piitulainen E, et al. Variability in densitometric assessment of pulmonary emphysema with computed tomography. Invest Radiol. 2005;40:777-83.

21. Stoel BC, Bakker ME, Stolk J, Dirksen A, Stockley RA, Piitulainen E, et al. Comparison of the sensitivities of 5 different computed tomography scanners for the assessment of the progression of pulmonary emphysema: a phantom study. Invest Radiol. 2004;39:1-7.

22. Gierada DS, Pilgram TK, Whiting BR, Hong C, Bierhals AJ, Kim JH, et al. Comparison of standard- and low-radiation-dose CT for quantification of emphysema. AJR Am J Roentgenol. 2007;188:42-7.

23. Heussel CP, Kappes J, Hantusch R, Hartlieb S, Weinheimer O, Kauczor HU, et al. Contrast enhanced CT-scans are not comparable to non-enhanced scans in emphysema quantification. Eur J Radiol. 2010;74:473-8.

24. Gierada DS, Yusen RD, Pilgram TK, Crouch L, Slone RM, Bae KT, et al. Repeatability of quantitative CT indexes of emphysema in patients evaluated for lung volume reduction surgery. Radiology. 2001;220:448-54. 